\title{
Plans for ICM 2022
}

\section{Andrei Okounkov}

The next International Congress of Mathematicians (ICM) will take place in Saint Petersburg, Russia, in July of 2022. ICMs are the largest and perhaps the most significant meetings in our profession. As we congratulate the organizers of ICM 2018 in Rio on the very successful realization of their plans, it is already time to start the preparations for the next congress.

Saint Petersburg occupies a very important place on the mathematical map of the world. This is the city in which Leonhard Euler spent 31 incredibly productive years, where Perelman proved Thurston's geometrization conjecture, where Chebyshev invented his polynomials, Markovhis processes, Lyapunov-his exponents, where analysis and mathematical physics were taken to new heights by Sobolev, Ladyzhenskaya, Faddeev, V. Smirnov, and their schools. This list can certainly be continued, but perhaps St. Petersburg's, and indeed Russia's, main asset is not the past accomplishments, but the students who are learning mathematics now, and who are curious, talented, and inspired to go further than their teachers and grandteachers. In connection with the ICM, 2022 will be declared the Year of Mathematics in the Russian Federation. One of its main objectives is to reach this talented youth, as well as to reinforce Russia's traditional broad public interest in mathematics.

Saint Petersburg, the second largest city in Russia, may not be quite the whirlwind of human activity that Moscow is, but it is second to none when it comes to architectural

Andrei Okounkov teaches mathematics at Columbia University, and also at Skoltech and Higher School of Economics in Moscow. He is a member of the ICM 2022 Organizing Committee. His email is okounkov@math.columbia.edu.

The author was a member of the team that prepared the St. Petersburg ICM bid and presented it to the General Assembly of the IMU in São Paulo. This paper outlines the central points of this document and of the organizers' plans.

For permission to reprint this article, please contact: reprint - permission@ams.org.

DOI: https://dx.doi.org/10.1090/noti 1801

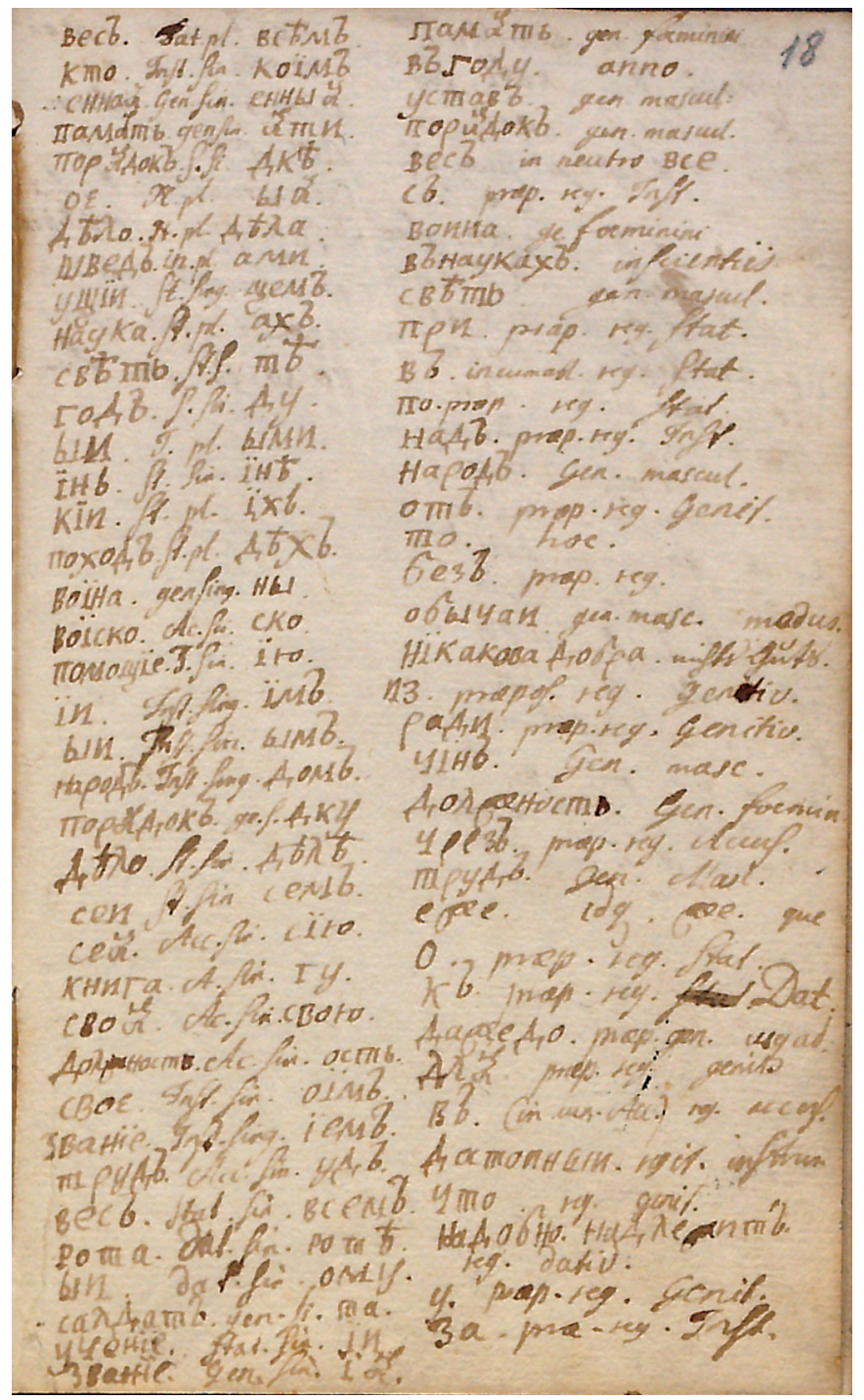

Figure 1. Euler's notebooks from the time he was learning Russian. The great mathematician had an excellent command of spoken and written Russian. 
and natural beauty, the treasures of its museums, the expression and perfection of its musical performances, and so many other things that attract millions of visitors every year. Many visitors come to take part in international congresses and conventions-St. Petersburg is a leading destination for international gatherings, hosting such high profile events as its annual international economic (SFIEF) and legal forums. The city is used to extending its warm hospitality on a really large scale: it hosted several games of the soccer World Cup in 2018 and will be welcoming soccer fans again for UEFA Euro 2020.

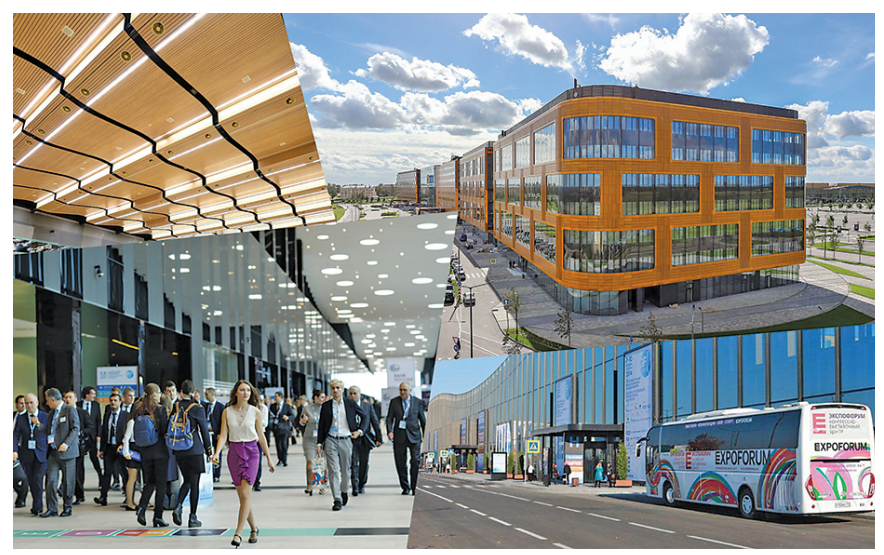

Figure 2. Views of the Expoforum convention and exhibition centre.

The venue for ICM 2022 will be the newly constructed, state-of-the-art Expoforum convention and exhibition centre. Its three pillar-free exhibition pavilions can be freely partitioned with mobile walls and can be transformed into comfortable congress halls of any size up to 8,600 participants. They come equipped with modern concert-quality sound, light, and projection systems. Energy spent on mathematics may be replenished at the two on-site hotels and a number of restaurants. As to the proverbial free lunches, the organizers are budgeting for free or significantly subsidized lunches for all registered participants, and are also planning a variety of options for meals and snacks. The Expoforum's catering service is experienced in welcoming guests with diverse dietary restrictions and needs.

Frequent special buses will bring ICM participants to the subway (15 $\mathrm{min}$ ) and to the city center (about $30 \mathrm{~min}$ ). The trip to the city center goes via one of the city's main arteries-Moskovsky Prospect. Along it, many more hotels are situated, making for convenient pickup and dropoff. The connection from the Expoforum to the Pulkovo International Airport is particularly easy and takes only a few minutes. Pulkovo has recently completed a large-scale upgrade and was recognized in 2015 as Europe's best airport. There will be people there to help ICM participants and no lines. Other convenient arrival options include high-speed trains and cruise ships.

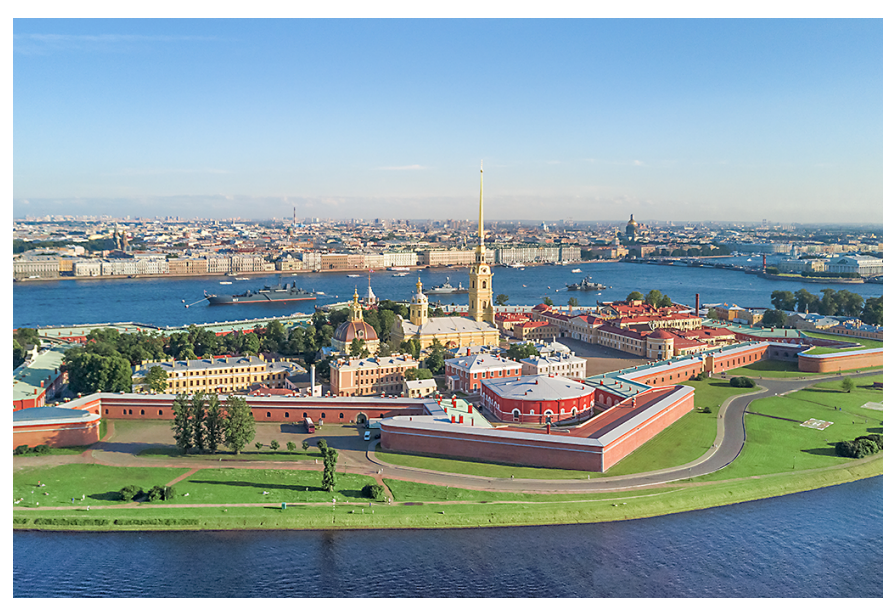

Figure 3. View of Saint Petersburg: the Peter and Paul fortress, the Neva River, the Winter palace (the Hermitage museum), and the Saint Isaac's cathedral in the background.

What should make getting to and around the ICM especially easy is the system that has been already proven effective during the World Cup and other large-scale international events. The ICM registration tag will work like the soccer Fan ID_it will eliminate the need for a visa, public transit tickets, etc. Registered participants will be able to print their tags before arriving in Russia, or at the airport. Its magic visa properties will extend well beyond the ICM itself, so that people can go to satellite events or tour Russia.

Meeting conveniences are, of course, only auxiliary to the quality of the ICM events themselves. The local organizers are confident that the IMU Program Committee will put together a superb collection of prize, plenary, and sectional talks and are preparing to complement them with top quality public lectures, industry events, exhibitions, and other activities. A new feature of ICM 2022 will be a crucial involvement of the newly created IMU Structure Committee in shaping the scientific program. The overall structure of ICM is certainly a topic that needs the thoughtful and careful attention of our whole community, and the people who represent it through IMU. Concerning ICM events that are within the influence of local organizers, we strongly encourage people to send their ideas and suggestions, either to us directly (see, e.g. my email address in the p 236 footnote.) or to one of the members of our distinguished International Advisory Committee.

Such input will be especially valuable because the organizers have in mind a large variety of events that go beyond the boundaries of mathematics as they may be narrowly defined. We are discussing plans for a festival of science films, a convention of science journalists, large-scale mathematics outreach events, and so on. We are discussing the possibility of having pretalks on the eve of plenary talks that will provide useful background information at a more comfortable pace. ICM outreach events will be naturally 


\section{COMMUNICATION}

crosslinked with the program of the Year of Mathematics in Russia mentioned above. Of course, we are also planning social events, like receptions, city and museum tours, special concerts and performances for ICM participants, etc. In fact, the dates of the ICM have been moved to July to make sure the participants catch more of the enchanting endless northern summer light and the various festivals inspired by it.

Another direction in which local organizers are inviting international participation is the organization of satellite events. St. Petersburg was created as Russia's window on the Baltic and Europe and is within easy reach of many centers of mathematics and conference venues of great historical significance. In our budget, we should have means to cosponsor many satellite events. Of course, we hope that people who come to Russia for the ICM will also take time to tour some of the so many exciting destinations within Russia. An excellent opportunity for this is to team up with some local people to run a satellite at one of the many potential locations. The strengthening of ties between the Russian and the international mathematics community is certainly among the major goals of the organizers.

An important feature of our budget is a very extensive financial and logistic help for many categories of ICM participants. Following Russia's longstanding tradition of reaching out to our colleagues in developing countries, 1,000 of them will receive full financial support. The recipients will be chosen by the IMU and it is very important to get the word out early and widely. Up to 200 invited speakers will also be fully supported. We are planning to support an additional 1,300 young mathematicians from all over the world in partnership with their local societies and science foundations. A possible arrangement could be: the local organizers pay local expenses while the participant's travel expenses are covered at home. We are hoping the AMS, and others societies and funding agencies worldwide, will find this cooperation proposal attractive.

Even people paying the registration fee in full, which we estimate to be less than US\$200, will probably find it very reasonable given what we are planning to provide in return: a tablet with a congress app, free mobile access for the ICM duration, ICM proceedings, medical and accident insurance for the duration of the event, the aforementioned free lunches, free conference dinner, free public transport, and at least one free social and one cultural event. This all in addition to the intangibles of being in the middle of the most exciting mathematics there is.

The organizers believe they are working for an excellencause and are determined to make the 2022 ICM a successful and impactful event. We are reaching out to the readers of the Notices and to the whole mathematics community for their input in planning the event; we hope to see everybody in St. Petersburg in 2022!

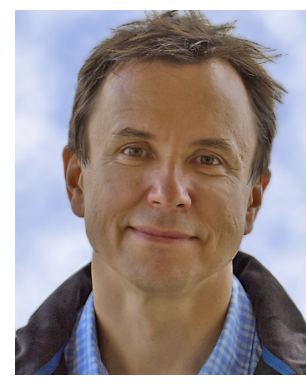

Andrei Okounkov

\section{Credits}

Figure 1 is courtesy of the St. Petersburg Branch of the Archive of the Russian Academy of Sciences.

Figure 2 is the author's collage of images by Expoforum International Ltd.

Figure 3 is courtesy of the city of St. Petersburg. 